\title{
Translation into Brazilian portuguese and validation of the psoriasis family index
}

Tradução e validação do instrumento índice de qualidade de vida para familiares de pacientes com psoríase para o português falado no Brasil

\author{
Juliana Catucci Boza ${ }^{1}$ \\ Rafaela Caminha Vanin ${ }^{3}$ \\ Magda Blessmann Weber ${ }^{4}$
}

\author{
Mohammad K. A. Basra ${ }^{2}$ \\ Renata Rosa Carvalho ${ }^{3}$ \\ Tania Ferreira Cestari ${ }^{5}$
}

DOI: $h$ ttp://dx.doi.org/10.1590/abd1806-4841.20131911

\begin{abstract}
Psoriasis Family Index is a quality of life instrument for family members of patients with psoriasis developed in English. The aims of this study were to translate the Psoriasis Family Index into Brazilian Portuguese, culturally adapt it and verify its reliability and validity. The study followed these two steps: 1) Translation, linguistic and cultural adaptation, 2) Validation. The translated Psoriasis Family Index showed high internal consistency and high test-retest reliability, confirming its reproducibility. The Portuguese version of the Psoriasis Family Index was validated for our population and can be recommended as a reliable instrument to assess the QoL of family members and partners of patients with psoriasis.
\end{abstract}

Keywords: Indicators of quality of life; Psoriasis; Quality of life

Resumo: Psoriasis Family Index é um instrumento para aferição da qualidade de vida em familiares de pacientes com psoríase, desenvolvido em língua inglesa. O objetivo deste estudo é traduzir o Psoriasis Family Index para o Português, adaptá-lo culturalmente e determinar sua confiabilidade e validade. Foi realizado em duas etapas: 1) tradução, adaptação cultural e linguística e 2) validação. O Psoriasis Family Index traduzido demonstrou alta consistência interna e alta confiabilidade de teste e reteste, confirmando sua reprodutibilidade. A versão brasileira do Psoriasis Family Index foi validada para nossa população e pode ser recomendada como uma ferramenta na avaliação da influência da psoríase na família dos pacientes.

Palavras-chave: Indicadores de qualidade de vida; Psoríase; Qualidade de vida

Psoriasis is a chronic inflammatory disease affecting skin, scalp, nails and occasionally joints. Similarly to other chronic skin diseases, the impact of psoriasis extends beyond the patients' quality of life (QoL), affecting their family and partners., ${ }^{1,2}$ Measuring the secondary impact of psoriasis on the health-related quality of life (HRQoL) of family members of psoriasis patients is a fundamental aspect of the treatment of the disease. Moreover, it is helpful as an additional instrument to evaluate endpoints in clinical practice and studies ${ }^{3,4}$

The Psoriasis Family Index (PFI) is a 15-item

Received on 03.06.2012.

Approved by the Advisory Board and accepted for publication on 27.07.2012.

Work conducted at the Department of Dermatology - Hospital de Clínicas de Porto Alegre (HCPA). Universidade Federal do Rio Grande do Sul (UFRGS). Porto Alegre (RS), Brazil.

Conflict of interest: None

Financial Support: Research Investment Fund of the Hospital de Clínicas de Porto Alegre (Fundo de Investimento em Pesquisa do Hospital de Clínicas de Porto Alegre)

Dermatologist. Hospital de Clínicas de Porto Alegre (HCPA). Universidade Federal do Rio Grande do Sul (UFRGS). - Porto Alegre (RS), Brazil

Department of Dermatology - Cardiff University School of Medicine - Wales, United Kingdom.

Medical Student - Universidade Federal do Rio Grande do Sul (UFRGS). - Porto Alegre (RS), Brazil.

Associate Professsor of Dermatology - School of Medicine, Universidade Federal de Ciências da Saúde de Porto Alegre (UFCSPA) - Porto Alegre (RS), Brazil.

Associate Professor of Dermatology, School of Medicine, Universidade Federal do Rio Grande do Sul (UFRGS) - Hospital de Clínicas de Porto Alegre (HCPA).

Porto Alegre (RS), Brazil. 
questionnaire that was developed and validated in the Department of Dermatology of the Cardiff University School of Medicine by Finlay et al. ${ }^{4}$ The authors published the preliminary results and concluded that PFI was easy to understand, administer and answer, in addition to being effective in evaluating the impact of psoriasis on family members/relatives of patients with the disease.

The validated questionnaires for the measurement of QoL are mostly developed for English speaking populations. Therefore, it is usually necessary to adapt these questionnaires in terms of language and culture. With this in mind, the aim of this study was to translate the PFI from English into Brazilian Portuguese, culturally adapt it to our population, and verify its reliability and validity.

The study followed the steps proposed by the World Health Organization for QoL questionnaires and was developed in agreement with the original authors in 2 steps:

1. Translation and linguistic and cultural adaptation: This part of the study was conducted by the joint work of 10 pairs of patient/relatives, 3 translators, a psychiatrist, a nurse and the English and Portuguese authors;

2. Validation: The study population comprised a convenience sample of psoriasis patients and family members or partners accompanying patients to their routine outpatient appointments at the Dermatology Outpatient Clinic of the Clinics Hospital of Porto Alegre. For the family members/partners to be included in the study, the patient had to have psoriasis diagnosed more than 1 year before recruitment. The family members/partners were excluded if they suffered from any skin disease, including psoriasis or any chronic nona-dermatological condition.

Disease severity was measured by the Psoriasis Area and Severity Index (PASI)6 and Patient Quality of Life (QoL) was assessed by the Dermatology Life Quality Index (DLQI)7 and Psoriasis Disability Index (PDI).$^{5-8}$ The partners or family members recorded how they perceived the severity of the patients' psoriasis on a $0-10$ visual analogue scale (Family Global Assessment, FGA), with 0 indicating cleared psoriasis and 10 indicating very severe psoriasis. Family members' QoL was assessed by the Brazilian version of PFI.

A total of 68 pairs of a psoriasis patient and a close relative/partner formed the baseline validation population. The BP-PFI (Brazilian Portuguese Psoriasis Family Index) showed high internal consistency (Cronbach's alpha $=0.91)$ and high test-retest reliability (intraclass correlation coefficient $=0.70$ ). The mean score of the population for PFI-15 BP was 11 (range $=0-34)$, PASI was 7.39 (range $=0.3-69.6)$, DLQI was 8 (range: 0-28), PDI was 12 (range: 0-41), and FGA

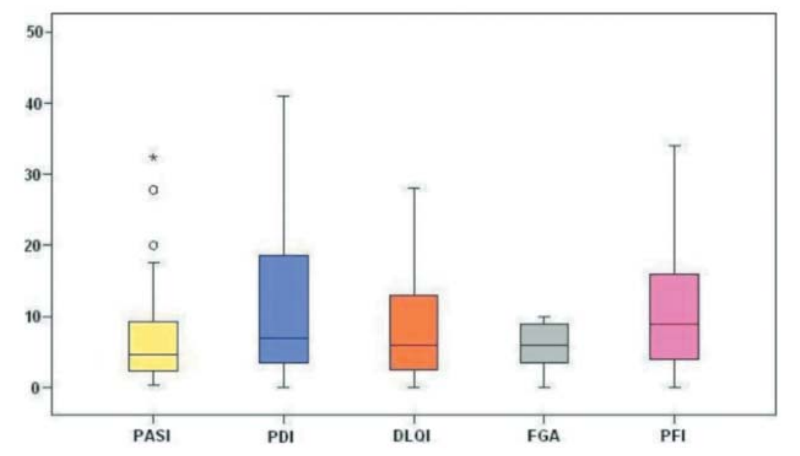

GRAPH 1: Scores of PASI, PDI, DLQI, FGA and PFI

TABLE 1: Results of the original PFI in comparison with the Brazilian version of PFI

\begin{tabular}{lll}
\hline & Original PFI & Translated PFI \\
\hline Cronbach`s alpha & 0.86 & 0.91 \\
CCI* $^{*}$ & 0.93 & 0.70 \\
PFI X DLQI & $\mathrm{r}=0.54$ & $\mathrm{r}=0.50$ \\
PFI X PDI & $\mathrm{r}=0.59$ & $\mathrm{r}=0.61$ \\
PFI X PASI & $\mathrm{r}=0.43$ & $\mathrm{r}=0.38$ \\
PASI X FGA & $\mathrm{r}=0.49$ & $\mathrm{r}=0.54$ \\
\hline
\end{tabular}

was 6.09 (range: 2-10).

Besides that, there was a significant correlation between families' PFI scores and DLQI scores $(\mathrm{r}=0.5$, $\mathrm{p}<0.001)$, PDI scores $(\mathrm{r}=0.61, \mathrm{p}<0.001)$, PASI scores $(\mathrm{r}$ $=0.38, \mathrm{p}<0.001)$ and FGA $(\mathrm{r}=0.49, \mathrm{p}<0.01)$, as shown in graph 1.

Table 1 demonstrates the results of the BP-PFI in comparison with the original version.

Psoriasis has a clear impact on the patient's QoL and on their family. The secondary impact of psoriasis on family members and its implications for the patient's QoL and severity of the disease have been evaluated in recent studies. ${ }^{2-4}$ The use of PFI could be a complementary tool in measuring the impact of psoriasis and showing different aspects of a patient's life. PFI allows us to capture specific issues related to psoriasis, including some extra housework such as laundry and cleaning due to messy, greasy scales treatment and vacuuming of skin flakes.

The Brazilian Portuguese version of PFI was validated for our population and it could be recommended as a reliable measure to assess the QoL of family members and partners of Brazilian patients with psoriasis. 


\section{REFERENCES}

1. Martins GA, Arruda L, Mugnaini ASB. Validation of life quality questionnaires for psoriasis patients. An Bras Dermatol. 2004;79:521-35.

2. Eghlileb AM, Davies EE, Finlay AY. Psoriasis has a major secondary impact on the lives of family members and partners. Br J Dermatol. 2007;156:1245-50.

3. Basra MK, Edmunds 0, Salek MS, Finlay AY. Measurement of family impact of skin disease: further validation of the Family Dermatology Life Quality Index (FDLQI). J Eur Acad Dermatol Venereol. 2008;22:813-21.

4. Eghlileb AM, Basra MK, Finlay AY. The psoriasis family index: preliminary results of validation of a quality of life instrument for family members of patients with psoriasis. Dermatology. 2009;219:63-70.

5. Fredriksson T, Pettersson U. Severe psoriasis - oral therapy with a new retinoid Dermatologica. 1978:157:238-44.

6. Finlay AY, Khan GK. Dermatology Life Quality Index (DLQI), a simple practical measure for routine clinical use. Clin Exp Dermatol. 1994;19:210-6.

7. Finlay AY, Kelly SE. Psoriasis - An index of disability. Clin Exp Dermatol. 1987;12:8-11.

8. Lewis VJ, Finlay AY. Two decades experience of the Psoriasis Disability Index. Dermatology. 2005;210:261-8.

\author{
MAILING ADDRESS: \\ Juliana CatucciBoza \\ Rua Ramiro Barcelos 2350 - zona 13 - Rio Branco \\ 90035-003 - Porto Alegre - RS \\ Brazil \\ E-mail:juliana_boza@yahoo.com.br
}

How to cite this article: Boza JC, Basra MKA, Vanin RC, Carvalho RR, Weber MG, Cestari TF. Translation into brazilian portuguese and validation of the psoriasis family index. An Bras Dermatol. 2013;88(3):482-4. 